\title{
Single lead atrial synchronised pacing in patients with cardiogenic shock after acute myocardial infarction
}

\author{
M B FOWLER, J C P CRICK, D I TAYLER, M J ENGLISH, D J WOOLLONS, A D TIMMIS \\ R VINCENT, D A CHAMBERLAIN \\ From the Department of Cardiology, Royal Sussex County Hospital, Brighton; and the Division of Biomedical \\ Engineering, University of Sussex, Falmer, Brighton
}

SUMMARY A pacing system requiring only a single lead was used to establish atrial synchronised pacing in eight patients with complete atrioventricular block and cardiogenic shock following acute myocardial infarction. Spontaneous atrial activity was sensed through electrodes positioned on the pacing lead and used to trigger ventricular demand pacing. A normal atrioventricular relation could be established in each of these critically ill patients without the complexity of inserting and finding a stable position for an additional atrial sensing lead.

Atrial synchronised pacing at the spontaneous sinus rate had distinct haemodynamic advantages compared with conventional ventricular pacing at 100 beats $/ \mathrm{min}$. Mean cardiac output for the group was $3.3 \mathrm{l} / \mathrm{min}$ with atrial synchronised pacing compared with $2.6 \mathrm{1} / \mathrm{min}$ with conventional pacing, a significant difference of $27 \%$. Peak systolic pressure averaged respectively 91 and $73 \mathrm{~mm} \mathrm{Hg}$ in the two pacing modes. With conventional ventricular pacing a pronounced phasic alteration in blood pressure was observed, dependent on the altering relation of the paced beats to spontaneous atrial activity. Atrial synchronised pacing abolished this effect and resulted in a stable blood pressure at or above the peak pressure achieved with conventional pacing.

Atrial synchronised pacing with a single lead system can be established rapidly. This mode of pacing has appreciable and significant haemodynamic superiority over conventional ventricular pacing in patients with cardiogenic shock and atrioventricular block following acute myocardial infarction.

Most patients who develop complete atrioventricular block following prolonged myocardial ischaemia have inferior infarction associated with failure of conduction at the level of the atrioventricular node.' The escape rhythm, commonly of junctional origin, is reliable, and ventricular pacing is not usually required. ${ }^{2}$ In contrast, the majority of patients with anterior infarction (and only a few with inferior infarction ${ }^{3}$ ) complicated by complete atrioventricular block have unreliable escape foci of ventricular origin, having

Requests for reprints to Dr DA Chamberlain, Royal Sussex County Hospital, Brighton, Sussex BN2 5BE

Accepted for publication 26 January 1984

Present addresses: M B Fowler, Department of Cardiology, Stanford University, Stanford, California 94305, USA; J C P Crick, Guy's Hospital, London; D I Tayler, Northern General Hospital, Sheffield; M J English, School of Engineering and Applied Sciences, Sussex University, Falmer, Brighton; D J Woollons, School of Engineering and Applied Sciences, Sussex University, Brighton; A D Timmis, Guy's Hospital, London. sustained extensive myocardial necrosis. Pacing is mandatory, but the prognosis remains poor because of associated cardiogenic shock. ${ }^{45}$

Under these circumstances the haemodynamic advantages of re-establishing atrioventricular synchronisation $^{6^{-9}}$ may be particularly important. But the difficulty of inserting and finding a stable position for a second (atrial) lead under emergency conditions has been a major factor in hindering the widespread adoption of this "physiological" mode of pacing. Moreover, the value of an atrial contribution to cardiac output in patients with raised left ventricular filling pressure is controversial.1011 Small haemodynamic benefit may be thought not to justify the complexity of the procedure.

We report the use of a pacing system (prototype Telectronics Sussex AV pacemaker), initially developed at Sussex University, 12 which requires only a single lead to achieve atrial synchronised ventricular pacing. The potential advantages of this form of pac- 
ing for patients with complete heart block and cardiogenic shock have been assessed by comparing haemodynamic variables during conventional and atrial synchronised pacing.

\section{Patients and methods}

Measurements were made in eight patients during emergency pacing following acute myocardial infarction. All had cardiogenic shock with peripheral vasoconstriction, a systolic blood pressure of less than 90 $\mathrm{mm} \mathrm{Hg}$, and anuria. The ages of the six men and two women ranged from 57 to 76 (mean 63) years. The site of infarction was inferior in four, anterior in two, and indeterminate in two. The indication for pacing was asystole in three patients or complete atrioventricular block with a heart rate of less than 50 beats $/ \mathrm{min}$ in the remaining five (four of whom had had ventricular fibrillation).

In six of the patients a 6 French quadrapolar temproary pacing lead (USCI) was inserted percutaneously via a subclavian vein with the tip positioned near the apex of the right ventricle. The lead has a distal pole and three others 10,15 , and $20 \mathrm{~cm}$ from the tip. The indifferent pole for both pacing and sensing was the most proximal and lay in the superior vena cava. Electrograms were recorded from both poles which lay within the atrium: the pole detecting the larger atrial signal was selected for unipolar atrial sensing. In the remaining two patients a pacing wire with a choice of four atrial poles was used.

A prototype Telectronics Sussex AV synchronous pacemaker was connected to the common indifferent, the ventricular, and the selected atrial pole. The pacemaker functions as a unipolar or bipolar atrial synchronised ventricular inhibited unit. The stimulus frequency is governed by atrial depolarisation signals in the atrial electrogram (corresponding to the $P$ waves of the surface electrocardiogram), but provision is made for continued safe pacing if the atrial rate should become unacceptably slow or fast. The unit functions as a ventricular demand pacemaker if atrial sensing is switched off. In this mode, stimulus frequency is determined by the "standby rate" setting, which also provides the "escape" rate during unexpected sinus slowing or failed atrial sensing. The upper rate limit is adjustable to a maximum of 150 beats/min. Above the upper rate limit each atrial depolarisation will cause ventricular pacing with increasing delay until eventually the stimulus following a $\mathbf{P}$ wave is blocked mimicking spontaneous Wenckebach periods.

A triple lumen thermodilution Swan-Ganz catheter (Edwards Laboratories Inc) was inserted through the same subclavian vein. Cardiac output was measured by the thermodilution technique (Edwards
Laboratories Inc, cardiac output computer number 9520 ) using an OMP injector gun to inject $10 \mathrm{ml}$ of $5 \%$ dextrose at room temperature. Five readings were recorded at each setting. Solitary aberrant readings were rejected. In one patient cardiac output measurements were not available because of a computer fault.

A short Teflon cannula inserted into the radial artery was used to record blood pressure. All pressures were measured with reference to the sternal angle using Statham P23Db transducers and were recorded together with an electrocardiogram on a fibreoptic medical recorder (Cambridge Scientific Instruments $\mathrm{Ltd}$ ). If phasic variation was considerable an average was taken of peak and trough measurements.

Atrial synchronised pacing, with heart rate controlled by sinus activity, was established in all the patients, and haemodynamic measurements were recorded once these had stabilised. The patients were then paced in conventional demand mode at 100 beats/min for at least five minutes, and the haemodynamic measurements were repeated.

The procedure was fully explained to all the patients, but signed formal consent was not sought because haemodynamic monitoring is performed routinely in our unit for patients who are critically ill with cardiogenic shock. Student's $t$ test for paired data was used for statistical comparisons.

\section{Results}

The Table summarises the principal haemodynamic effects of conventional ventricular pacing at 100 beats/min and atrial synchronised pacing at the spontaneous heart rate. Fig. 1 shows the change in cardiac output and stroke volume in the seven patients from whom measurements were obtained. In every case cardiac output was higher with atrial synchronised pacing, the mean increment for the group being $27 \%$ $(p<0.005)$. In two patients the synchronised pacing rate rose to 130 beats/min, and consequently their stroke volumes fell slightly.

Conventional pacing caused a pronounced phasic variation in systemic blood pressure (Fig. 2) dependent on the altering relation between atrial contraction and paced beats. We also noticed a tendency for the arterial pressure to continue to fall during the period of conventional pacing. Atrial synchronised pacing abolished the phasic variation and resulted in a stable pressure at or above the peak reading recorded during conventional pacing. Systolic pressure was augmented more $(73-91 \mathrm{~mm} \mathrm{Hg}$ ) than diastolic pressure $(47-54 \mathrm{~mm} \mathrm{Hg}$ ), and consequently pulse pressure was increased $(26-37 \mathrm{~mm} \mathrm{Hg})$.

Mean right atrial pressure fell significantly from 10 
Table Comparison of haemodynamic variables during standard ventricular pacing (VVI) at 100 beats per minute and atrial synchronised pacing $(V D D)$. Values are means $\pm S E M$.

\begin{tabular}{|c|c|c|c|}
\hline Haemodynamic variables & $V V I$ & $V D D$ & p value \\
\hline $\begin{array}{l}\text { Systolic blood pressure (mm Hg) } \\
\text { Diastolic blood pressure (mm Hg) } \\
\text { Systemic vascular resistance (units) } \\
\text { Heart rate (beats/min) } \\
\text { Cardiac output (1/min) } \\
\text { Stroke volume (ml) } \\
\text { Right atrial pressure (mm Hg) } \\
\text { Pulmonary artery systolic pressure (mm Hg) } \\
\text { Pulmonary artery diastolic pressure (mm Hg) }\end{array}$ & $\begin{array}{l}73 \pm 6 \\
47 \pm 3 \\
23 \cdot 9 \pm 2 \cdot 0 \\
100 \pm 0 \\
2 \cdot 6 \pm 0 \cdot 8 \\
26 \pm 3 \\
10 \pm 2 \\
28 \pm 4 \cdot 0 \\
19 \pm 2\end{array}$ & $\begin{array}{l}91 \pm 8 \\
54 \pm 3 \\
21 \cdot 9 \pm 1 \cdot 4 \\
105 \pm 13 \\
3 \cdot 3 \pm 0 \cdot 8 \\
33 \pm 4 \\
5 \pm 1 \\
32 \pm 3 \cdot 0 \\
19 \pm 2\end{array}$ & $\begin{array}{l}p<0.005 \\
p<0.05 \\
\text { NS } \\
\text { NS } \\
p<0.005 \\
p<0.05 \\
p<0.005 \\
p<0.005 \\
\text { NS }\end{array}$ \\
\hline
\end{tabular}

Pressure was recorded with reference to the sternal angle. (Reference to the mid-chest would require the addition of about $5 \mathrm{~mm} \mathrm{Hg}$.) NS, not significant.

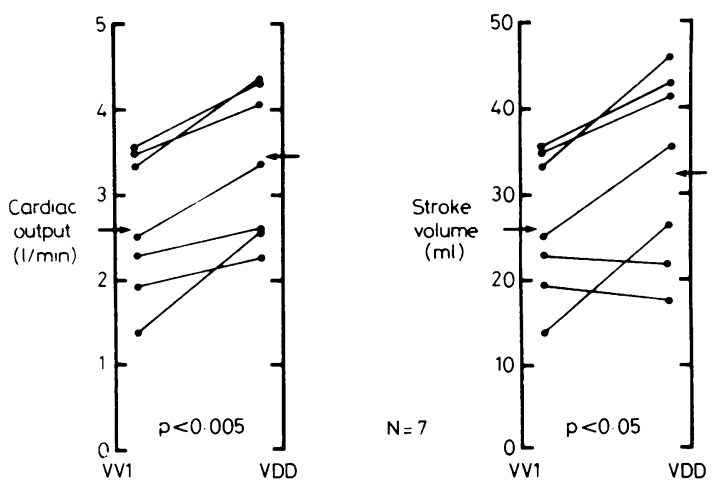

Fig. 1 Cardiac output and stroke volume in individual patients with conventional ventricular pacing (VVI) at 100 beats/min and atrial synchronised pacing (VDD). The arrows represent mean values for the group. to $5 \mathrm{~mm} \mathrm{Hg}$ as a result of atrial synchronised pacing $(p<0.005)$, but pulmonary artery end diastolic pressure was not altered consistently. Systemic vascular resistance was slightly higher during conventional ventricular pacing, but the change did not reach statistical significance.

In all the patients an appreciable clinical deterioration was observed during the short periods of conventional pacing. In two this was manifest by a deteriorating level of consciousness.

\section{Discussion}

The patients whom we studied were characterised by having cardiogenic shock. Seven of the eight had been resuscitated from ventricular fibrillation or prolonged asystole before pacing was established, and all remained in a critical condition during ventricular pacing. We could not determine the optimal ventricu-

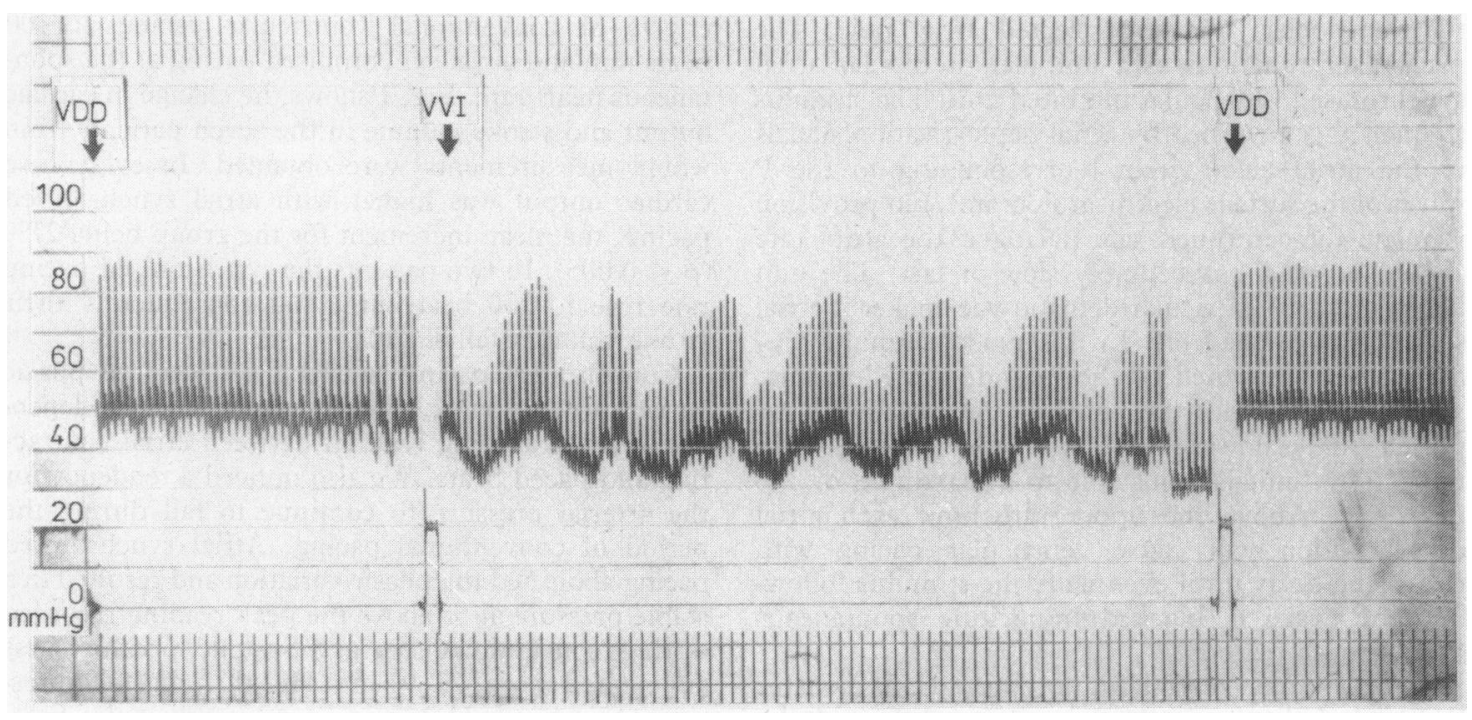

Fig. 2 Radial artery pressure tracing during atrial synchronised pacing (VDD) and conventional ventricular pacing (VVI) at 100 beats/minute in an individual patient. 
lar pacing rate in individual patients as prolonged observation in this mode would have caused further haemodynamic deterioration. We chose a rate of 100 beats/min as a standard for comparison with atrial synchronised pacing because this has been shown previously to provide optimal haemodynamic benefit in most patients in heart block following myocardial infarction. ${ }^{13}$

Our results show that restoration of a normal physiological relation between atrial and ventricular contraction has significant haemodynamic advantages over conventional ventricular pacing in patients with cardiogenic shock following acute myocardial infarction. In every case the haemodynamic benefit was matched by obvious clinical improvement with evidence of better peripheral perfusion and sometimes an improved level of consciousness. Conventional ventricular pacing was associated with a pronounced phasic variation in systolic blood pressure, which was abolished by the restoration of normal atrioventricular relations during atrial synchronised pacing. The improvement in systolic blood pressure was matched by a concomitant increase in cardiac output. The only haemodynamic variable that did not improve consistently during physiological pacing was the raised left ventricular filling pressure (measured indirectly as pulmonary artery end diastolic pressure). A prompt fall would not be expected, however, if the output of both ventricles improved equally.

Unfortunately, despite the demonstrable haemodynamic advantage of atrial synchronised pacing none of the patients in this study regained spontaneous atrioventricular conduction. Their condition remained critical and all the patients subsequently deteriorated and died after periods of atrial synchronised pacing ranging from four hours to six days. In other patients with atrioventricular block complicating anterior infarction, paced before cardiogenic shock had supervened, atrial synchronisation produced similar haemodynamic benefits associated with recovery of conduction and prolonged survival. These patients did not meet the criterion for inclusion in the present report.

The single lead system overcomes important disadvantages of physiological pacing. It is particularly suited for use in patients who are critically ill and least able to tolerate the delay caused by insertion of a second lead. Indeed atrial synchronised pacing was successfully initiated in three patients during cardiopulmonary resuscitation for ventricular standstill. No special skills are required above those necessary for conventional pacing.

The prototype Telectronics Sussex AV synchronous external pacemaker employs sensing circuits using timing, filtering, and signal comparison to separate the atrial and ventricular electrograms. It was possible to sense atrial electrograms down to a nominal $0.1 \mathrm{mV}$. Because of unstable electrograms, there were occasional instances of failed atrial tracking seen in every patient. The pacemaker then functioned correctly as a conventional pacing unit at the set standby rate. In none of the patients were these failed sensing periods prolonged.

Our experience with the prototype unit has strengthened our belief that atrial synchronised pacing is the most suitable mode for patients with initially impaired myocardial function. The single lead system has shown that the haemodynamic benefits of atrial synchronisation can be achieved without sacrificing simplicity of lead insertion or the speed with which pacing can be initiated.

\section{References}

1 Rosen KM, Loeb HS, Chuquimia R, Sinno MZ, Rahimtoola SH, Gunnar RM. Site of heart block in acute myocardial infarction. Circulation 1970; 42: 925-33.

2 Chamberlain D, Leinbach $\mathbf{R}$. Electrical pacing in heart block complicating acute myocardial infarction. $\mathrm{Br}$ Heart $\mathcal{F} 1970 ; 32$ : 2-5.

3 Tans AC, Lie KI, Durrer D. Clinical setting and prognostic significance of high degree atrioventricular block in acute inferior myocardial infarction: a study of 144 patients. Am Heart $\mathcal{F} 1980$; 99: 4-8.

4 Godman MJ, Lassers BW, Julian DG. Complete bundle-branch block complicating acute myocardial infarction. $N$ Engl f Med 1970; 282: 237-40.

5 Norris RM, Mercer CJ, Croxson MS. Conduction disturbances due to anteroseptal myocardial infarction and their treatment by endocardial pacing. Am Heart $f$ 1972; 84: 560-6.

6 Samet P, Castillo C, Bernstein WH. Hemodynamic sequelae of atrial, ventricular, and sequential atrioventricular pacing in cardiac patients. Am Heart $\mathcal{f}$ 1966; 72: 725-9.

7 Chamberlain DA, Leinbach RC, Vassaux CE, Kastor JA, DeSanctis RW, Sanders CA. Sequential atrioventricular pacing in heart block complicating acute myocardial infarction. $N$ Engl $\mathcal{J}$ Med 1970; 282: 577-82.

8 Karlöf I. Haemodynamic effect of atrial triggered versus fixed rate pacing at rest and during exercise in complete heart block. Acta Med Scand 1975; 197: 195-206.

9 Hartzler GO, Maloney JD, Curtis JJ, Barnhorst DA. Hemodynamic benefits of atrioventricular sequential pacing after cardiac surgery. Am $\mathcal{f}$ Cardiol 1977; 40: 232-6.

10 Greenberg B, Chatterjee K, Parmley WW, Werner JA, Holly AN. The influence of left ventricular filling pressure on atrial contribution to cardiac output. Am $\mathcal{F}$ Heart 1979; 98: 742-51.

11 Reiter MJ, Hindman MC. Hemodynamic effects of acute atrioventricular sequential pacing in patients with left ventricular dysfunction. Am $\mathcal{F}$ Cardiol 1982; 49: 687-92.

12 Chamberlain DA, Woollons DJ, White NM, English MJ. Synchronous AV pacing with a single pervenous electrode [Abstract]. Br Heart F 1973; 35: 559.

13 Lassers BW, Anderton JL, George M, Muir AL, Julian DG. Hemodynamic effects of artificial pacing in complete heart block complicating acute myocardial infarction. Circulation 1968; 38: $308-23$. 